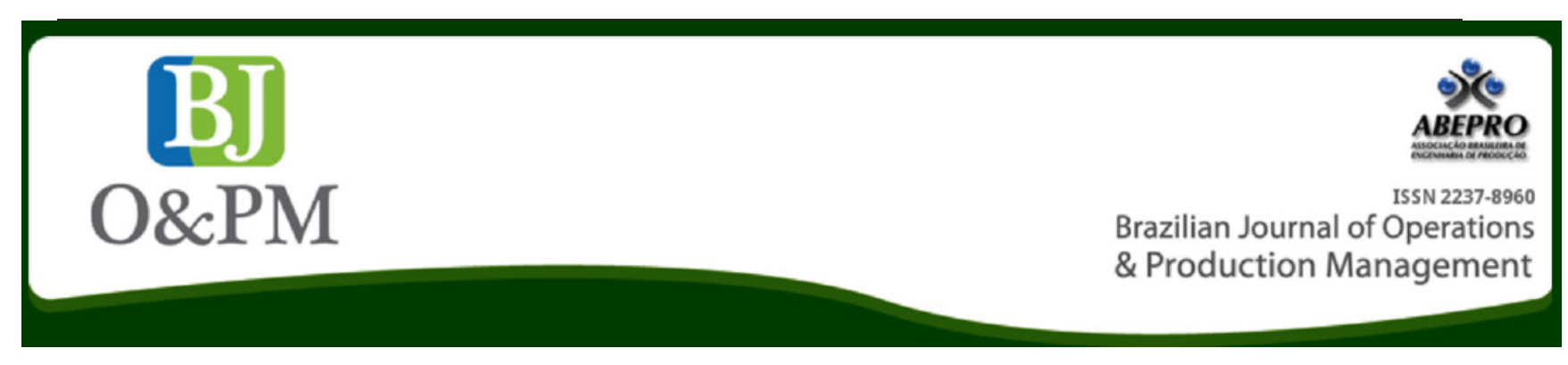

\title{
PROPOSAL FOR A LOW-COST TECHNIQUE FOR REMOTE MONITORING OF BODY TEMPERATURE: AN APPLICATION FOR WORK SAFETY
}

Sergio Gustavo Medina Pereiraa; Franciele Alves dos Santos Medina ${ }^{a}$; Rodrigo Franco Gonçalves ${ }^{a}$; Sergio Schina de Andrade ${ }^{b}$

\footnotetext{
a Universidade Paulista (UNIP) - São Paulo, SP, Brazil

${ }^{b}$ ECIL Energia - Santana de Parnaiba, SP, Brazil
}

\begin{abstract}
Purpose - This study aims to propose a cost-effective technical solution in monitoring the distance of workers operating in hazardous areas or under strong external influences.

Design/methodology/approach - The methodology that was used is a literature review in two steps; a) Papers basis were survey for the data search without filter; b) It was included a filter in the research from the year 2010.

Findings - A prototype was built to measure body temperature, relative air humidity and ambient temperature through of an applied research. As a result, the system's first tests were stable solution and for using open source tools it was possible to develop a low cost prototype.
\end{abstract}

Research limitations/implications - The limitation of this work is that only were monitored body temperature, environment and humidity. In the future will be included monitoring of heart rate, blood pressure, and resistance galvanometer.

Practical implications - Body temperature data is displayed in a graph, within a predetermined period, wherein the measurement range can be easily set.

Originality/value - The system may assist in the efficiency of diagnosis by providing the data in real time, allowing a professional of health more reliability when analyze the historical of data.

Keywords: body temperature, mobile health, occupational health, safety, prototype, monitoring. 


\section{INTRODUCTION}

Safety in the workplace is a topic that triggers many studies and raises some discussions on appropriate measures to be met by the organizations.

Sinelnikov et al., (2015) asserts that when organizations increase health and safety at work for an important organizational value, it is expected considerable investments in resources for measurement and performance. The growth and popularization of systems aimed at occupational safety and health had significant rise in the world from the 90's which generates a significant increase in concern and adequacy of performance measurement techniques and tools.

When dealing with occupational health and safety, you can see two approaches, one which deals with security related to handling equipment and the second addressing workers' health (Sinelnikov et al., 2015).This research addresses the prevention of accidents with a focus on health and well being of the person, considering that working environments should provide good conditions for workers, as follows: appropriate temperature and humidity, light enough, among others.

An important point is the well being of workers who labor in environments with extreme situations; external work is an example where they face very high or low temperatures. Workers with excessive exposure to heat can suffer elevation of body temperature and sleepiness can lead to physical collapse (Steen, 2001; Alahmer et al., 2011; Medeiros et al., 2013).

In this context, the biggest challenge is to detect the oscillation of the worker's body temperature in the workplace, performed remotely, and how health professionals can intervene before any type of abnormality occurs, which can cause more serious accident. And also when there is the need to maintain a continuous patient monitoring. The updating of vital data is essential for obtaining successful treatment of diseases considered critical, such as the treatment of diabetic patients in which the aim is to keep the level of insulin at a level considered stable and vital to the survival of the same. Thus, there are systems capable of monitoring the insulin level in real time, such as equipment CGMS (continuous glucose monitoring system) of Meditronic - Multinational development of medical equipment, which ended up being the most widely used equipment worldwide (Minicucci et Franco, 2010).

The choice of remote monitoring system topic of body temperature wireless emerged in order to give more aid to those involved in risky activities and who need real-time monitoring. A large part of the initiatives related to safety and health of workers are still evaluated precariously. Outdated based on metrics such as the mortality rate and injury accidents.
It is noticed that these measures focused on failure ever conducted, evaluated after the incident, are less useful to assist organizations in their decision-making and actions for continuous improvement (Sinelnikov et al., 2015). The system helps the efficiency of diagnosis by providing the data in real time, allowing health professionals to greater safety due to the possibility of a historical analysis of data, allowing predict or foresee a situation that may expose the worker to a hazardous situation which consequently lead to occurrence of an accident.

This study is an applied research that aims to present a low-cost solution for remote and real-time monitoring of body temperature. This aimed at workers who put up with in hazardous areas. The device performs the measurements and makes access and the faster and more accurate service, acting to prevent possible accidents.

This paper is organized as follows: initially it presented the theoretical concepts of health and safety at work, telemetry and related work. Section 3 deals with the methodology adopted. Section 4 examines the issues relating to the monitoring system. Section 5 is the results. Finally, Section 6 contains a summary of the work, final considerations, limitations and future work.

\section{LITERATURE REVIEW}

\subsection{Occupational health and safety at work}

For Fiedler et al., (2010), the work environment consists of a combination of several interrelated factors. They act directly or indirectly on the quality of life of workers and of their own work results. Some of these negative factors cause malaise, discomfort, thereby increasing the risk of accidents, which can cause considerable damage to workers' health.

It was identified by Lida (2005), that a major source of stress at work are unfavourable environmental conditions such as excessive heat, humidity, noise and vibration, that influence directly and negatively on the performance of human labor.

Sinelnikov et al., (2015), discuss the differences in terms used in the measurement of indicators related to safety at work, although there is standardization there are still many close terms, and used interchangeably. The main points observed on the indicators are: feasibility, significance, transparency, ease of communication, validation, utility. They were identified as part of the utmost importance on the quality of metrics. It emphasizes that the most important of the main indicators is the use of the object itself, that is, its main purpose is to identify the steps to reduce or eliminate the risk. 
Al-Shanini et al., (2014) addresses the accidents in process / factory plants in order to keep the economy at desired levels. It also debates that the process plants are often equipped with a comprehensive process control system to ensure smooth operation and to prevent accidents. The system provides protection through different degrees of automation, facilitated by human intervention and protected by additional layers of protection as mitigating measures in case the system fails. An effective means of combating accidents is to formulate appropriate preventive measures. However, this is difficult to realize unless accidents can be predicted and are completely understood, before it is identified the occurrence of an accident.

Koskela (2014) discusses about the social responsibility of corporations, which identifies three key factors in this process: the economy, the environment and social impacts. In their study the author uses the backdrop of this division, but addresses the issue of health and safety at work in the section on social impacts. In this context the responsibility of organizations is internal or external. It is understood that the company should provide a safe and healthy work environment in both cases.

In their studies Fan et al., (2014), point the economic factors involved in occupational safety and health. He asserts that the governments of developed countries have to pay close attention to security issues and Occupational Health. According to these numbers it was observed that approximately U\$ 583 million are earmarked for this sector annually. Despite these investments occupational accidents and diseases are still common factors in the removal and termination of employees. It was found that in the US about 4 million are injured in their workplace each year and about 13 workers die each day. Related losses amount to U\$ 170 billion each year according to 2003 data, with a significant increase when compared to the '90s.

The study of the development of DIMOR-TC also deals with the prevention of accidents but focused on the person / employee before the employee has any ailment that can take you to shoot a possible accident the device to recognize and avoid the failures and incidents that refer to workers' health and can be minimized.

According to Lee (1996), the safety is directly involved with the organizational culture and the culture he defined as a "product of the individual and the group as: values, attitudes, perceptions, competencies and patterns of behaviour that determine the health management commitment and safety of the organization."

Fan et al., (2014), in his literature systematic review reports relevant data on the number of studies conducted in the area. Through Figure 1, it can be observed that the concern for occupational health and safety had considerable grown in 2008, with a fall in 2010 and growing back in 2012.

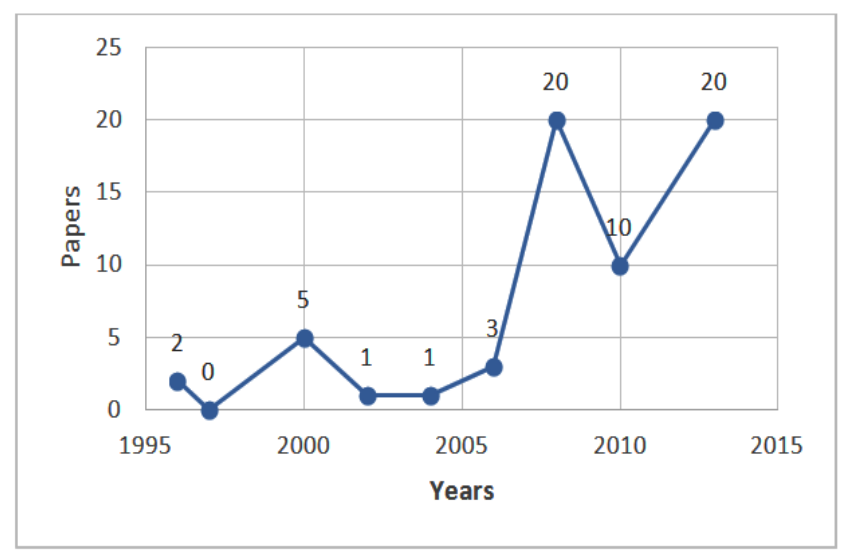

Figure 1. Growth of the number of safety and health publications in the workplace

Source: Compiled from Fan et al (2014)

From these data we note that studies focused area still have much importance, the increasing amount of publications show the interest in the subject matter.

\subsection{Telemetry}

The word Telemetry is from Greek origin, and it means far remote, and ?, meaning measure (Dias, 1992).

The possibility of monitoring remote systems is applied when the systems are classified with a high level of importance or dangerous, unhealthy or not favor the existence of human life, and when there is the need for a high level of monitoring. Systems capable of performing such activities are called telemetry systems.

With the progress of technology, telemetry has become necessary for the development of various systems and is applied to the aid of different fields such as medicine, engineering, safety, geography and so on. Telemetry is also used in the biological area allowing the collection of biological data from aquatic animals. (ABECASIS, 2009), the monitoring of agricultural machinery used in planting, cultivating and harvesting products (Piovesan, 2008), among others.

\subsection{Related work}

As technological advances occur, there are a variety of electronic devices. A problem observed in technological innovations is that for the most part of these artifacts reaches the consumer with a very high price. 
Table 1. Shows the similar research conducted in the field of health informatics.

\begin{tabular}{|c|c|}
\hline General Objective & References \\
\hline $\begin{array}{l}\text { System that connects the patient, locat- } \\
\text { ed in your home, health professionals, } \\
\text { integrating the various relevant services } \\
\text { to remote monitoring of patient health. }\end{array}$ & $\begin{array}{l}\text { Carvalho and } \\
\text { Filho (2011). }\end{array}$ \\
\hline $\begin{array}{l}\text { System that connects the home of } \\
\text { the patient and a web server where } \\
\text { mobile phones interact with a service } \\
\text { Webservice for sending patient infor- } \\
\text { mation. }\end{array}$ & $\begin{array}{l}\text { Machado et al } \\
\text { (2011). }\end{array}$ \\
\hline $\begin{array}{l}\text { A Pervasive and intelligent approach } \\
\text { Low Cost for Patient Monitoring with } \\
\text { Cardiovascular Diseases. }\end{array}$ & $\begin{array}{l}\text { Silva and Siebra } \\
\text { (2012). }\end{array}$ \\
\hline $\begin{array}{l}\text { Shimmer - a wireless sensor platform } \\
\text { for noninvasive biomedical research }\end{array}$ & $\begin{array}{l}\text { Burns et al } \\
\text { (2010). }\end{array}$ \\
\hline Information about the NeXus-10 & $\begin{array}{l}\text { Mind Media } \\
\text { (2011). }\end{array}$ \\
\hline $\begin{array}{l}\text { AMON: a wearable multiparameter } \\
\text { medical monitoring and alert system }\end{array}$ & $\begin{array}{l}\text { Anliker et al } \\
\text { (2004). }\end{array}$ \\
\hline $\begin{array}{l}\text { Mobile wearable device for long term } \\
\text { monitoring of vital signs. Computer } \\
\text { methods and program in Biomedicine. }\end{array}$ & $\begin{array}{l}\text { Klingeberg and } \\
\text { Schiling (2012). }\end{array}$ \\
\hline
\end{tabular}

\section{METHODOLOGY}

In a first step a survey of literature review was conducted. The databases used in the survey were: Science Direct, IEEE eXplore and Scholar Google.

The survey is composed of two stages. In the first stage, papers basis were survey for the data search without filter. After, this survey was included a filter in the research from the year 2010 in order to lift the state of the art.

The key words utilized were: telemetry, occupational health and safety, prototyping and telemedicine. In the second stage, table 1 in the Section 2.3 shows related works compiled by the topics.

To develop the prototype we used some concepts and methods of prototyping. The system constructions of the methodology are described in Section 4.

According to Choi et Chan (2013) using virtual prototyping, the system can be constructed for viewing and simulation engine to validate and enhance performance. In prototyping, failures related to development, design and planning could be detected before many expenses were compromised

We used the concept of prototyping proposed by Warfel (2009), as shown in Figure 2.

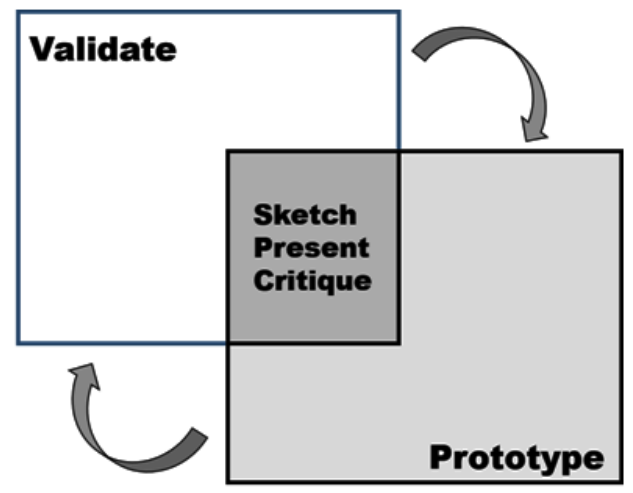

Figure 2: Diagram of the iterative design and critique process. Source: Compiled from Warfel (2009)

Preece et al. (2002) classifies prototype into two types: a) Prototypes Low Fidelity: which are those that do not resemble the final product and b) Prototypes of High Fidelity: are those that most resemble the final product.

Another aspect of prototyping techniques is the Mixed prototyping. It is an emerging approach for usability testing. It is considered as a multimodal environment, which can involve vision, hearing and touch providing better valuations in the analysis of the interrelationships between the physical form and behavior of products (Barbiere et al, 2013).

This research used physical prototyping concepts for the construction of electronic measuring device and for modeling interfaces and software development were included low-fidelity prototypes, wireframes to the screen.

\section{SYSTEM DEVELOPMENT METHOD}

For the first phase of the research, the literature search method through a literature review was used, available both in national international databases, for analysis of similar systems conducted in telemedicine, health informatics.

The second phase of the research involves the development of the prototype, construction and device test, hardware, to perform the sensing body temperature signals, environment and relative humidity, with the transmission of data collected to the WebService in real time. Finally after analysis of the data, they will be displayed graphically on an interface, within a predetermined period of time.

The developed system, referred to herein Body Temperature Monitoring Device (DIMOR-TC), consists of a device (hardware) with ability to perform body temperature sensing worker.

Figure 3 shows a block diagram, picturing the system development stages, from the measurement of data generated by the sensors, which is captured by the microcontroller and processes the data, eliminating noise and make the necessary amplification. 


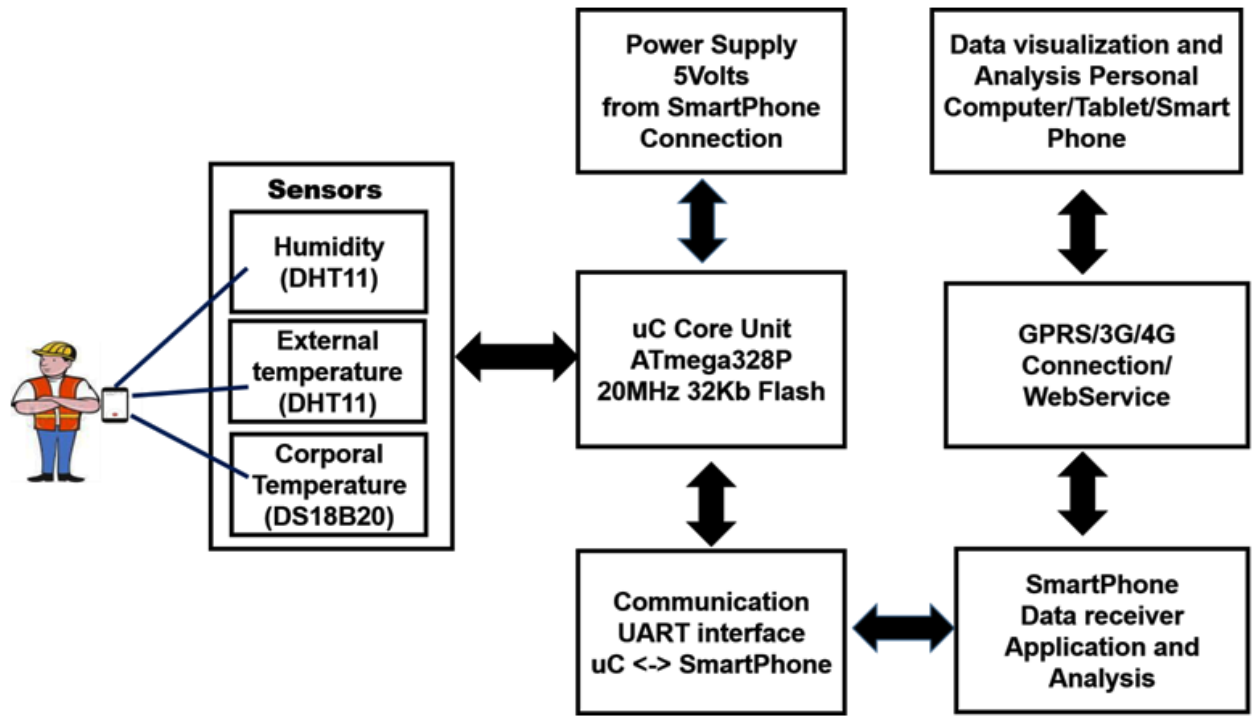

Figure 3. Blocks Diagram System Source: The authors own.

The prototype is connected to the worker's phone, so using the device's battery in the low power mode. An application shall transmit the data to a device chosen by the health professional who can view the data in graph form. The measurement data can be easily set, at predetermined time intervals.

Table 2 lists the current consumption in active mode and Low Power Mode. And the table 3 shows sampling frequency in Bytes per second.

Table 2. Current requirements in active mode and low power mode

\begin{tabular}{lcc}
\hline \multicolumn{1}{c}{ Component } & $\begin{array}{c}\text { Required } \\
\text { current at } \\
\text { Active Mode }\end{array}$ & $\begin{array}{c}\text { Required } \\
\text { current at } \\
\text { Low Power } \\
\text { Mode }\end{array}$ \\
\hline $\begin{array}{l}\text { DHT11- Humidity } \\
\text { and Temperature }\end{array}$ & $2.5 \mathrm{~mA}$ & $150 \mathrm{uA}$ \\
$\begin{array}{l}\text { DS18B20 - } \\
\text { Temperature } \\
\text { Atmega328P }\end{array}$ & $9 \mathrm{~mA}$ & $7.8 \mathrm{nA}$ \\
\hline
\end{tabular}

Source: The authors own.

Table 3. Current requirements in active mode and low power mode

\begin{tabular}{lcc}
\multicolumn{1}{c}{ Sensor } & $\begin{array}{c}\text { Sampling } \\
\text { Frequency }\end{array}$ & $\begin{array}{c}\text { Bytes per } \\
\text { second }\end{array}$ \\
\hline $\begin{array}{l}\text { DHT - Humidity and } \\
\text { Temperature }\end{array}$ & $1 \mathrm{KHz}$ & $5 \mathrm{kB} / \mathrm{s}$ \\
DS18B20 - Temperature & $1 \mathrm{KHz}$ & $5 \mathrm{kB} / \mathrm{s}$
\end{tabular}

Source: The authors own.

\section{RESULTS}

The remote device signals, specifically in this paper deal with the body temperature, relative humidity and ambient temperature (DIMOR-TC). Hardware and software have been developed with free platforms and open-source tools, allowing a reduction in costs and also in the final price.

By monitoring, the recorded data allow to create a history of the user, which allows the initiation of an abnormal event, sending alert signals to the health team and then to users themselves, which may stop or decrease your pace, or activity being performed. The device (DIMOR-TC) intends to act before there is a negative event, working to prevent these events.

The development of a system with an architecture that integrates sensors, mobile devices and Web Service to:

i) continually monitor the health of workers by sending alerts in case of emergency and

ii) the development of technical solution, considering a complete system (hardware and software) aimed at targeting telemetry wireless data transmission and real-time, with low cost limitations considered from the perspective of Systems Engineering.

\section{CONCLUSION}

The choice of remote monitoring of vital signs via wireless system theme emerged in order to give more aid to those involved in risky activities and who need real-time monitoring.

Because it is a mobile device, it has numerous applications, for instance: monitoring workers at risky areas or of difficult 
access, or in execution of tasks that can be considered dangerous to the worker. Thus, a skilled team can monitor workers without displacement and provide greater safety to the worker.

The system may assist in the diagnosis efficiency by providing the data in real time, allowing a professional of health greater safety due the possibility of a historical analysis of data.

In the market there are several products that measure body temperature, but the differential of DIMOR-TC is that it not only keeps a history of measurements performed on an electronic medical record but also measures the temperature and humidity of the environment where the measurement is being performed. This can be visualized in a graphic body temperature within a predetermined period. The measurement range can be easily configured.

In this paper, only one type of monitoring was addressed : the body temperature. As future work, it is planned to implement new aspects to the project, such as monitoring of heart rate, blood pressure, and galvanometer resistance (for measurement of stress), which would allow the system to perform more accurate diagnoses.

\section{REFERENCES}

ABECASIS, D. (2009), Telemetria: Conceitos e Aplicações. Algarve Portugal: Centro de Ciências do Mar- Universidade do Alga.

Alahmer, A., Omar, M. A., Mayyas, A. and Dongri, S. (2011), Effect of relative humidity and temperature control on in-cabin thermal comfort state: Thermodynamic and psychometric analyses. Applied Thermal Engineering 31 (2011) $2636 \mathrm{e} 2644$.

Al-Shanini, A., Ahmad, A. and Khan, F. (2014), Accident modelling and analysis in process industries. Journal of Loss Prevention in the Process Industries 32: 319-334.

Anliker, J. A., Ward, P., Lukowicz, G., Tröster, F., Dolveck, M. B. F., Keita, E. B., Schenker, F., Catarsi, L., Coluccini, A., Belardinelli, D., Shklarski, M., Alon, E., Hirt, R. and Schmid, M. (2004), AMON: a wearable multiparameter medical monitoring and alert system, IEEE Transactions on Information Technology in Biomedicine 8:415-427.

Barbieri, L., Angilica, A., Bruno, F. and Muzzupappa, M. (2013), Mixed prototyping with configurable physical archetype for usability evaluation of product interfaces. Computers in Industry 64, 310-323.

Burns, B. R., Greene, M. J., McGrath, T. J., O'Shea, B., Kuris, S. M., Ayer, F. and Stroiescu, V. (2010), Cionca Shimmer - a wireless sensor platform for noninvasive biomedical research, IEEE Sensors 10:1527-1534.
Carvalho, S. T., Copetti, A. and Filho, O. G. L. (2011), Ubiquitous computing system in home health care. J. Health Inform. 2: 51-7.

Choi, S.H and Chan, A.M.M. (2013), A virtual prototyping system for rapid product development. HongKong.

DIAS, O. (1996), Telemetria e sensoriamento remoto. São Paulo: Copel. Fan D, Lo C K Y, Ching V, Kan C W (2014). Occupational health and safety issues in operations management: A systematic and citation network analysis review. Int. J. Production Economics 158: 334-344.

Fiedler, N. C., Guimarães, P. P., Alves, R. T. and Wanderley, F. B. (2010), Avaliação ergonômica do ambiente de trabalho em marcenarias no sul do Espírito Santo. Revista Árvore $34: 5-12$.

Koskela, M. (2014), Occupational health and safety in corporate social responsibility reports. Safety Science 68:294-308.

Klingeberg, T. and Schilling, M. (2012), Mobile wearable device for long term monitoring of vital signs. Computer methods and program in Biomedicine 106:89-96 Lee T R (1996). Perceptions, atitudes and behaviour: the vital elements of a safety culture. Health Saf.10:1-15.

Lida, I. (2005), Ergonomia: projeto e produção. Edgard Blucher Ltda, São Paulo Machado A, Padoin E L, Salvadori F, Righi L, Campos M De, Sausen P S. E, Dil S L (2011). Utilização de Dispositivos Móveis, Web Services e Sotfware Livre no Monitoramento Remoto de Pacientes. CBIS.

Medeiros, E. G. S. de, Filho, F. A. G, Silva, L. B. da (2013), Proposta de avalização termoambiental em viaturas utilizadas nos serviços de radioparulhamento no estado da Paraiba. XXXIII ENCONTRO NACIONAL DE ENGENHARIA DE PRODUCAO.

Mind, M. B. V. (2011), Available via Information about the NeXus-10. http://www.mindmedia.nl/english/nexus10. php/. Cited July 2011.

Minicucci, W. J. and Franco, D. (2010), Monitorização contínua da glicose: Novas tecnologias. http://ebook. diabetes.org.br/component/k2/item/90-capitulo-2monitorizacao-continua-daglicose-novas-tecnologias.

Piovesan, F. C. (2008), Telemetria Aplicada na Mecanização Agrícola Utilizando o Datalogger CR 1000. Santa Maria.

Preece, J.; Rogers, Y., et Sharp, (2005), Design de Interação: além da interação homem-computador. Bookman.

Silva, M. D, and Siebra, C. A. (2012), Uma Abordagem Pervasiva e Inteligente de Baixo Custo para o Monitoramento de Pacientes com Doenças Cardiovasculares. XII Workshop de Informática Médica. 
Sinelnikov, S., Inouye, J. and Kerper, S. (2015), Using leading indicators to measure occupational health and safety Performance. Safety Science 72: 240-248

Steen, R. (2014), American Red Cross Offers Travel Safety Tips. The American National Red Cross. Available at: http:// www.redcross.org/ title of subordinate document. Cited 27 Dez 2014.

Warfel, T. Z., (2009), Prototyping: A Practitioner's Guide. Rosenfeld Media, New York, NY. 